University of Nebraska - Lincoln

DigitalCommons@University of Nebraska - Lincoln

$11-15-1991$

\title{
The process-controlled magnetic properties of nanostructured Co/Ag composite films
}

Sy_Hwang Liou

University of Nebraska-Lincoln, sliou@unl.edu

S. Malhotra

University of Nebraska - Lincoln

Z.S. Shan

University of Nebraska - Lincoln

David J. Sellmyer

University of Nebraska-Lincoln, dsellmyer@unl.edu

S. Nafis

University of Nebraska - Lincoln

See next page for additional authors

Follow this and additional works at: https://digitalcommons.unl.edu/physicsliou

Part of the Physics Commons

Liou, Sy_Hwang; Malhotra, S.; Shan, Z.S.; Sellmyer, David J.; Nafis, S.; Woollam, John A.; Reed, C.P.; DeAngelis, R.J.; and Chow, G.M., "The process-controlled magnetic properties of nanostructured $\mathrm{Co} / \mathrm{Ag}$ composite films" (1991). Si-Hwang Liou Publications. 45.

https://digitalcommons.unl.edu/physicsliou/45

This Article is brought to you for free and open access by the Research Papers in Physics and Astronomy at DigitalCommons@University of Nebraska - Lincoln. It has been accepted for inclusion in Si-Hwang Liou Publications by an authorized administrator of DigitalCommons@University of Nebraska - Lincoln. 


\section{Authors}

Sy_Hwang Liou, S. Malhotra, Z.S. Shan, David J. Sellmyer, S. Nafis, John A. Woollam, C.P. Reed, R.J. DeAngelis, and G.M. Chow 


\title{
The process-controlled magnetic properties of nanostructured $\mathrm{Co} / \mathrm{Ag}$ composite films
}

\author{
S. H. Liou, ${ }^{\text {a) }}$ S. Malhotra, ${ }^{\text {a) }}$ Z. S. Shan, ${ }^{\text {a) }}$ D. J. Sellmyer, ${ }^{\text {a) }}$ S. Nafis, ${ }^{\text {b) }}$ \\ John A. Woollam, ${ }^{\text {b) }}$ C. P. Reed, ${ }^{\text {c) }}$ and R. J. DeAngelisc) \\ Center for Materials Research and Analysis, University of Nebraska-Lincoln, Lincoln, \\ Nebraska 68588-0111 \\ G. M. Chow ${ }^{\text {d) }}$ \\ Center for Bio/Molecular Science and Engineering, Naval Research Laboratory, Washington, \\ DC 20375-5000
}

Nanostructured $\mathrm{Co} / \mathrm{Ag}$ composite films were prepared by magnetron sputtering using a single target. The average crystallite sizes of $\mathrm{Co}$ and $\mathrm{Ag}$ in the films depend on the deposition conditions. As the substrate temperature increases from $100^{\circ} \mathrm{C}$ to $600^{\circ} \mathrm{C}$, the average $\mathrm{Ag}$ crystallite size increases from 39 to $452 \AA$, and the average Co crystallite size increases from $<30$ to $297 \AA$ in the film with 39 vol. \% of Co. The films with 39 vol. \% of Co and prepared at $400{ }^{\circ} \mathrm{C}$ substrate temperature showed a maximum magnetic coercivity of 565 Oe at $6 \mathrm{~K}$. We have studied the correlation between the structure and magnetic properties of these films.

\section{INTRODUCTION}

Several methods have been developed during the last decades to prepare small particles. ${ }^{1,2}$ Fine dispersed magnetic particle systems are of interest because of the opportunities they present for atomic engineering of materials with specific properties. Specifically, the magnetic coercivity of nanometer size particles is greatly enhanced because a particle contains a single magnetic domain. For example, coercivities up to $3 \mathrm{kOe}$, which is two orders of magnitude higher than that of pure $\mathrm{Fe}$, have been achieved in granular $\mathrm{Fe}$ materials. These $2-20 \mathrm{~nm} \mathrm{Fe}$ clusters were embedded in insulators such as $\mathrm{SiO}_{2}$ or $\mathrm{Al}_{2} \mathrm{O}_{3}$. ${ }^{3}$ Such materials may have the potential to be used in high density magnetic recording, optical devices, and sensors.

Previous studies have been carried out on small magnetic clusters dispersed in a metal matrix, such as $\mathrm{Fc}_{\mathrm{c}}$ in a $\mathrm{Ag}$ matrix ${ }^{4}$ and $\mathrm{Fe}$ in a $\mathrm{Cu}$ matrix. ${ }^{5}$ In this article we show that a nanostructured composite material can also be formed by mixing $\mathrm{Co}$ and $\mathrm{Ag}$. The average crystallite size of these films can easily be controlled during the sputtering process by varying the substrate temperature. The correlations between the microstructural characteristics, in particular the crystallite size in the films, and the magnetic properties, are discussed.

\section{EXPERIMENTS}

The Co/Ag composite metal films were prepared by dc magnetron sputtering using a single target. The sputtering targets were made by sintering a mixture of $\mathrm{Co}$ and $\mathrm{Ag}$

\footnotetext{
a) Also at the Department of Physics and Astronomy.

${ }^{b)}$ Also at the Department of Electrical Engineering and Center for Microelectronic and Materials Research.

c) Also at the Department of Mechanical Engineering.

d) Also at the Geo-Center, Inc., Fort Washington, MD.
}

powders. The films were prepared with the substrate temperature varied from $100^{\circ} \mathrm{C}$ to $600^{\circ} \mathrm{C}$. The sputtering gas was 4 mTorr of Ar. The process conditions for making $\mathrm{Co} / \mathrm{Ag}$ composite films are similar to those of $\mathrm{Fe} / \mathrm{Ag}^{4}$ Film compositions were determined by using energy dispersive $\mathrm{x}$-ray analysis in a scanning electron microscope. The structure of films was investigated using a Rigaku $x$ ray diffractometer with a $\mathrm{Cu}$ source. The magnetization and coercive force were measured using a commercial SQUID magnetometer.

\section{RESULTS AND DISCUSSION}

The films used in this study have compositions near $\mathrm{Co}_{19} \mathrm{Ag}_{81}$ (13 vol. \% of $\mathrm{Co}$ ) and $\mathrm{Co}_{50} \mathrm{Ag}_{50}$ (39 vol. \% of $\mathrm{Co}$. The variation in composition of the films prepared at different substrate temperatures was less than 5 at. $\%$.

The $\mathrm{x}$-ray diffraction patterns of $\mathrm{Co} / \mathrm{Ag}$ composite films with 39 vol. \% of Co prepared at substrate temperatures $\left(T_{s}\right)$ from $100^{\circ} \mathrm{C}$ to $600^{\circ} \mathrm{C}$ are shown in Fig. 1. It clearly shows that the films prepared at higher substrate temperature are mixed with the crystallites of the face center cubic (fcc) Ag and fcc Co. We would like to discuss some of features in this figure: the fcc $\mathrm{Co}(200)$ peaks in the films with $T_{s}>400^{\circ} \mathrm{C}$, the peak position shift of the $\mathrm{Ag}(111)$ and $\mathrm{Co}(200)$ with variation in $T_{s}$, and systematical decreasing line widths of the diffraction peaks with increasing $T_{s}$. The strong fcc $\mathrm{Co}(200)$ difraction peaks observed in these films indicate that most Co clusters have the fcc structure. The $d$ spacings of $\operatorname{Ag}(111)$, which were calculated from the $2 \theta$ value of $\mathrm{Ag}(111)$, increases from 2.33 to $2.35 \AA$ as the $T_{s}$ increased from $100^{\circ} \mathrm{C}$ to $300^{\circ} \mathrm{C}$. The $d$ spacing of $\mathrm{Ag}(111)$ prepared at a low substrate temperature $\left(<300^{\circ} \mathrm{C}\right)$ is smaller than that of the bulk silver element. This is expected if we allow a small amount of cobalt to mix with the silver during deposition. Al- 


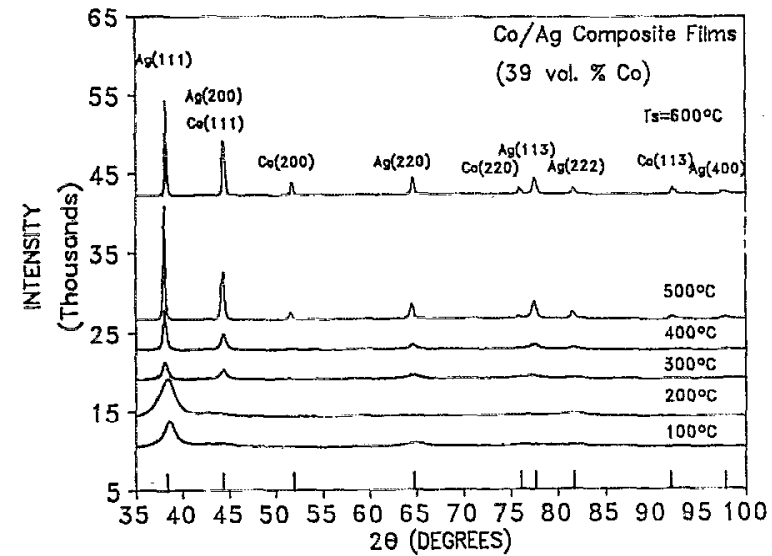

FIG. 1. Co/Ag composite films prepared at substrate temperatures of (a) 100 , (b) 200 , (c) 300 , (d) 400 , (e) 500 , and (f) $600^{\circ} \mathrm{C}$.

though the mutual solubility of $\mathrm{Ag}$ and $\mathrm{Co}$ under equilibrium conditions is very low in both the solid and liquid form, an alloy of Co-Ag may form under fast quenching conditions. The amount of Co mixed in the Ag crystal matrix in the film prepared at a $100^{\circ} \mathrm{C}$ substrate temperature is estimated to be about $5 \%$ if we assume that the alloying of $\mathrm{Co}$ and $\mathrm{Ag}$ follows Vegard's law. ${ }^{6}$ The films prepared at a $T_{s}>300^{\circ} \mathrm{C}$ have much less alloying between the $\mathrm{Co}$ and $\mathrm{Ag}$ as evidenced by the closeness of the $d$ spacing of the film's fcc $\mathrm{Ag}$ (111) and $\mathrm{Co}(200)$ planes with that of the bulk Ag and Co, respectively. These results are similar to the results obtained on $\mathrm{Fe} / \mathrm{Ag}$ films prepared under the same conditions.

The line width of the $\mathrm{Ag}(111)$ and $\mathrm{Co}(200)$ Bragg peaks decrease with increasing $T_{s}$, as can be seen in Fig. 1 . This clearly indicates that the crystallite size of $\mathrm{Ag}$ and $\mathrm{Co}$ is changing with $T_{s}$. The average crystallite sizes were calculated from the shape of the $\mathrm{Ag}(111)$ and $\mathrm{Co}(200)$ peaks using the theory of Warren and the computational technique described previously. ${ }^{7,8}$ The average crystallite size of $\mathrm{Co}$ and $\mathrm{Ag}$ in the $\mathrm{Co} / \mathrm{Ag}$ films with 39 volume fraction of Co vs $T_{s}$ is shown in Fig. 2. As $T_{s}$ increases from $100^{\circ} \mathrm{C}$

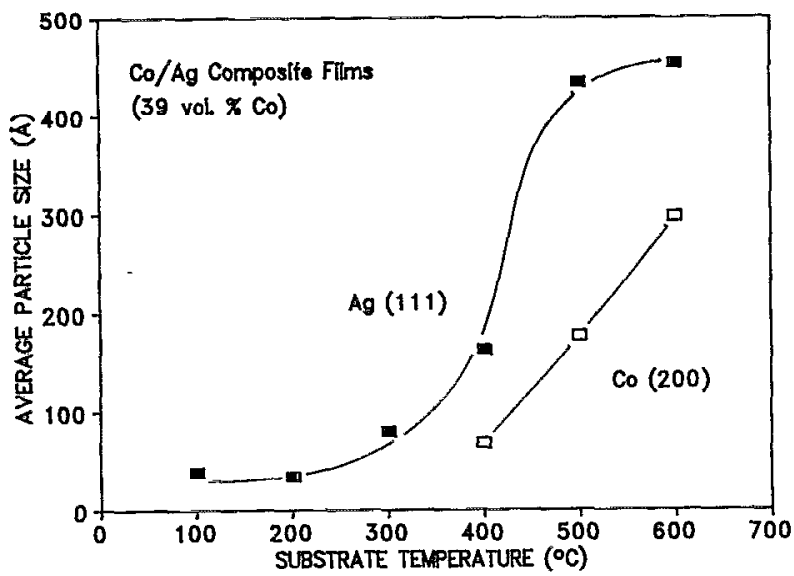

FIG. 2. Average particle size in $\mathrm{Co} / \mathrm{Ag}$ composite films (39 vol. \% of Co) vs substrate temperature.
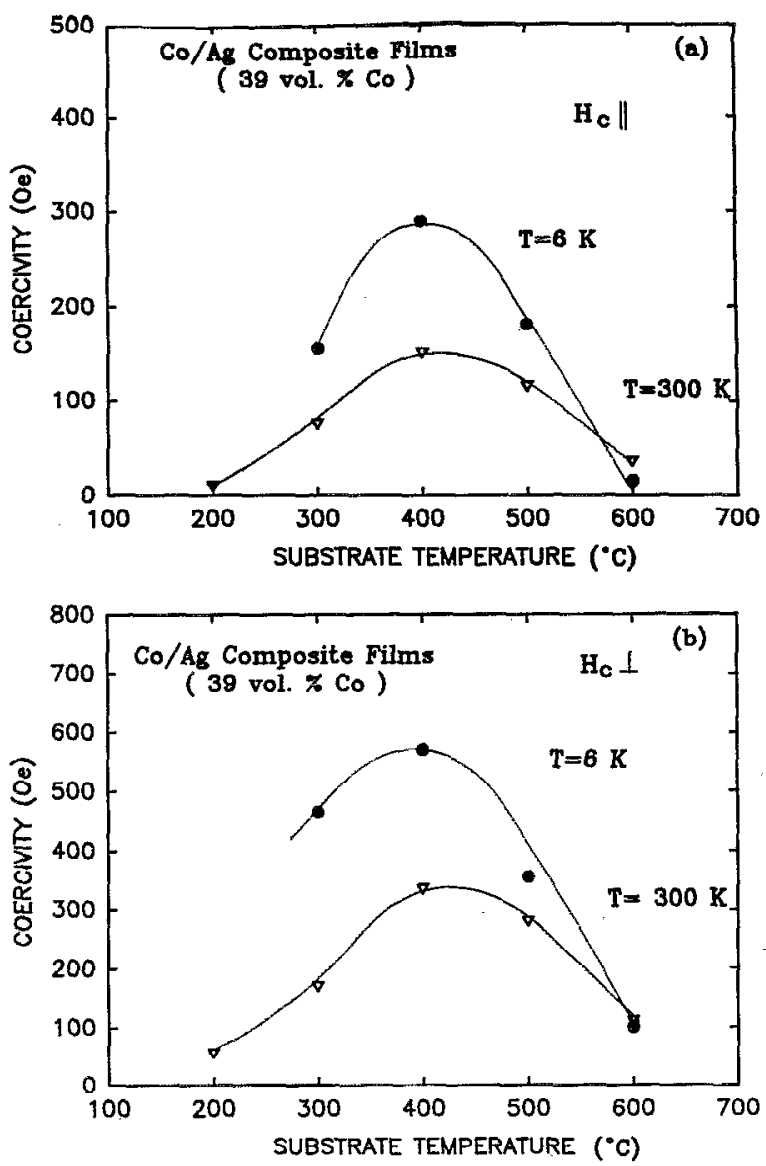

FIG. 3. Magnetic coereivitics at 300 and $6 \mathrm{~K}$ of $\mathrm{Co} / \mathrm{Ag}$ composite films containing $39 \mathrm{vol}$. \% of $\mathrm{Co}$ deposited at various substrate temperatures. (a) measured when the applied field was parallel to the film surface; (b) measured when the applied field was perpendicular to the film surface.

to $600{ }^{\circ} \mathrm{C}$, the average $\mathrm{Ag}$ crystallite size in the film increases from 39 to $452 \AA$, and the average Co crystallite size increases from $68 \AA$ at $T_{s}=400^{\circ} \mathrm{C}$ to $297 \AA$ at $T_{s}$ $=600^{\circ} \mathrm{C}$, respectively. The $\mathrm{Co}(200)$ peaks of the films prepared at $T_{s}<300^{\circ} \mathrm{C}$ were not able to be resolved even at counting times of $20 \mathrm{~s}$ per $0.002^{\circ}$ step in $2 \theta$. This is considered to be due to an extremely small crystallite size $<30 \AA$.

The magnetic coercivity measured at $300 \mathrm{~K}$ and $6 \mathrm{~K}$ of films with 39 vol. \% of Co versus the substrate temperatures is shown in Fig. 3. The $H_{c}$ measured with the magnetic field parallel to the film surface is shown in Fig. 3(a) and the $H_{c}$ measured with the magnetic field perpendicular to the film surface is shown in Fig. 3(b). The $H_{c}$ 's increase with increasing $T_{s}$ and reach a maximum for the films prepared at $400^{\circ} \mathrm{C}$ substrate temperature. An $H_{c}$ as high as $565 \mathrm{Oe}$ at $6 \mathrm{~K}$ has been achieved [see Fig. 3(b)]. It is known that the coercivity of the particles has a striking dependence on their size. As the particle size is reduced, it is typically found that the coercivity increases, goes through a maximum, and then tends toward zero. This magnetic behavior is due to the mechanism of the magnetization reversal which depends on the particle size. At large sizes, magnetization is changed by domain wall motion which takes much less energy. The result is small 


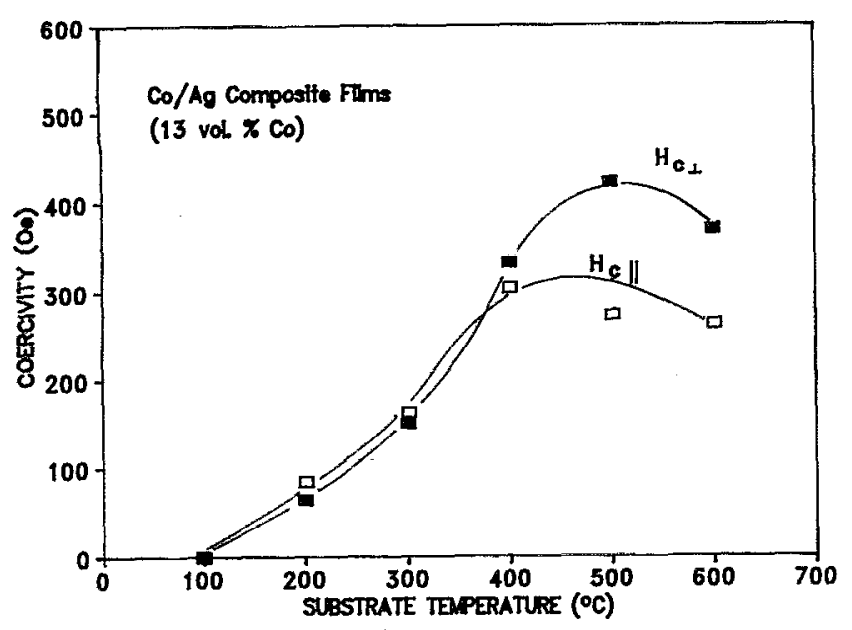

FIG. 4. Magnetic coercivities measured at $300 \mathrm{~K}$ with the applied field parallel and perpendicular of $\mathrm{Co} / \mathrm{Ag}$ composite films containing 13 vol. \% of Co deposited at various substrate temperatures.

coercivity. Below a critical diameter $D_{s}$, which depends on the alloys, the particles become single domains. In this size range the coercivity reaches a maximum and their magnetization is changed by spin rotation which usually requires a larger energy than domain wall motion. Below a critical diameter $D_{s}$, the coercivity decreases again because of thermal effects which will cause the spontaneous rotation of spin. Such particles are called superparamagnetic. The behavior of $H_{c}$ found in Co/Ag composite films, as shown in Fig. 3, can be correlated with their particle sizes. When $H_{c}$ is a maximum, the magnetic particles are single-domain sized. The critical diameter for a cobalt crystallite is about $100 \AA$ which is in good agreement with the single domain size reported by Luborsky. ${ }^{9}$

The magnetic coercivity measured with the applied field parallel $\left(H_{\|}\right)$and perpendicular $\left(H_{1}\right)$ to the film surface versus substrate temperature of films with a lower volume fraction of $\mathrm{Co}(13 \mathrm{vol}$. \% of $\mathrm{Co}$ ) is shown in Fig. 4. The magnetic properties of these films are similar to those observed in the films of high volume fraction cobalt, with two notable exceptions. The maximum coercivity occurs $100^{\circ} \mathrm{C}$ higher at a $T_{s}=500^{\circ} \mathrm{C}$. The other difference is the decrease in the anisotropy observed in the 13 vol. \% Co compared with the 39 vol. \% Co films.

The magnetic coercivity versus the temperature of films prepared at $T_{s}=400^{\circ} \mathrm{C}$ is shown in Fig. 5. $H_{c}$ is observed to decrease as the temperature increases. This is due to the thermal effects for the single domain particles. The temperature dependence of coercivity for noninteracting spherical or equiaxial single-domain particles is given by

$$
H_{c}=H_{c i}\left[1-\left(T / T_{B}\right)^{1 / 2}\right],
$$

where $H_{c i}$ is the coercivity at $0 \mathrm{~K}$ and $T_{B}$ is the blocking temperature, above which the material is superparamagnetic. The magnetic coercivity of film at a temperature above $T_{B}$ is zero. ${ }^{10}$ The $T_{B}$ of films prepared at $T_{s}$ $=400^{\circ} \mathrm{C}$ is much higher than $400^{\circ} \mathrm{C}$; therefore, the direct

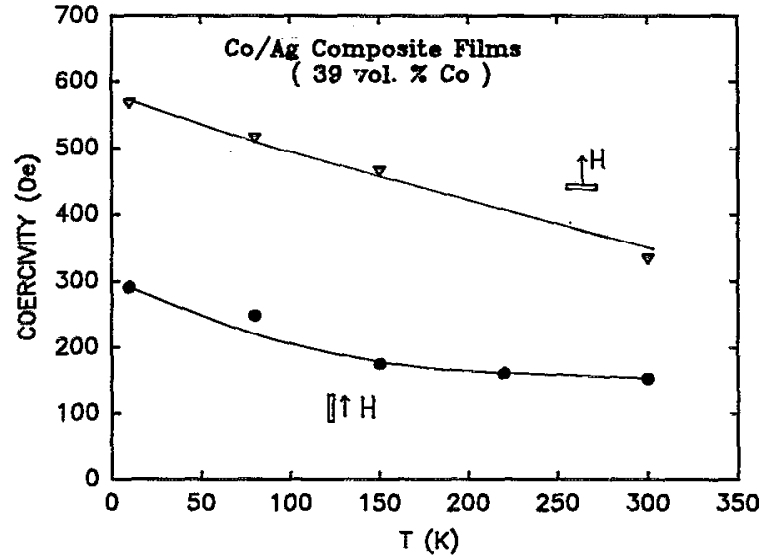

FIG. 5. The coercivity vs temperature of films with 39 vol. \% of Co prepared at $T_{s}=400^{\circ} \mathrm{C}$.

measurement of $T_{B}$ is not possible. As shown in Fig. 5, the observed $H_{c}$ versus temperature measured with magnetic field both perpendicular and parallel to the film surface is clearly not a function of $T^{1 / 2}$. The non- $T^{1 / 2}$ dependence is a strong indication that this film contains interacting crystallites. One would expect that the growth morphology in metal-metal films is under partial wetting conditions which may produce complex shaped networks rather than those made up of spherical clusters.

\section{SUMMARY}

We have synthesized $\mathrm{Co} / \mathrm{Ag}$ composite metal films with nanometer sizes of $\mathrm{Co}$ and $\mathrm{Ag}$ crystallites. Both $\mathrm{Co}$ and $\mathrm{Ag}$ crystallites have a fcc structure. The sizes of crystallite increase with increasing substrate temperature. A much enhanced magnetic coercivity was observed when the average Co crystallite size was the size of a single domain.

This work was supported by the University of Nebraska Foundation, NSF Grant DMR-8918889 and Center for Materials Research and Analysis at the University of Nebraska-Lincoln.

${ }^{1}$ See Physical Phenomena in Granular Materials, edited by G. D. Cody, T. H. Geballe, and P. Sheng, Materials Research Society Symposium Proceedings (Materials Research Society, Pittsburgh, 1990), Vol. 195.

${ }^{2}$ See Multicomponent Ultraf ine Micrastructures, edited by L. E. McCandlish, D. E. Polk, R. W. Siegel, and B. H. Kear, Materials Research Society Symposium Proceedings, (Materials Research Society, Pittsburgh, 1989), Vol. 132.

${ }^{3}$ S. H. Liou and C. L. Chien, Appl. Phys. Lett. 52, 512 (1988).

${ }^{4}$ S. H. Liou, Y. X. Zhang, and R. J. DeAngelis, Mater. Res. Soc. Symp. Proc. 195, 451 (1990).

${ }^{5}$ J. R. Childress, C. L. Chien, and M. Nathan, Appl. Phys. Lett. 56, 95 (1990).

${ }^{6} \mathrm{C}$. S. Barrett and T. B. Massalski, Structure of Metals, 3rd ed. (McGraw-Hill, New York, 1966), p. 357.

${ }^{7}$ B. E. Warren, $X$-ray Diffraction (Addison-Wesley, Reading, MA, 1969), p. 251.

${ }^{8}$ H. K. Kuo, P. Ganesan, and R. J. DeAngelis, Micro-struct. Sci. 8, 311 (1980).

${ }^{9}$ F. E. Luborsky, J. Appl. Phys. 32, $171 \mathrm{~S}$ (1961).

${ }^{10}$ B. D. Cullity, Introduction to Magnetic Materials (Addison-Wesley, Menlo Park, CA, 1972. 